\title{
lleo-ileal intussusception and gastrointestinal bleeding caused by incidental heterotopic pancreas: four case reports
}

\author{
Linping Cao ${ }^{1 \#}$, Wenxuan $\mathrm{Wu}^{2 \#}$, Diyu Chen ${ }^{2}$, Jiawei Hong ${ }^{2}$, Jian $\mathrm{Wu}^{1,2}$, Shusen Zheng ${ }^{1,2}$ \\ ${ }^{1}$ Division of Hepatobiliary and Pancreatic Surgery, Department of Surgery, First Affiliated Hospital, School of Medicine, Zhejiang University, \\ Hangzhou, China; ${ }^{2}$ Key Laboratory of Combined Multi-organ Transplantation, Ministry of Public Health, First Affiliated Hospital, Zhejiang \\ University School of Medicine, Hangzhou, China \\ \#These authors contributed equally to this work. \\ Correspondence to: Shusen Zheng, Jian Wu. First Affiliated Hospital, No.79 Qingchun Road, Hangzhou 310003, China. Email: shusenzheng@zju.edu.cn; \\ drwujian@zju.edu.cn.
}

\begin{abstract}
Heterotopic pancreas (HP) is a developmental anomaly defined as aberrantly located pancreatic tissue with no anatomical, vascular, or neural connection to the pancreas. Bowel intussusception and gastrointestinal bleeding caused by isolated HP is extremely rare. This study explores the clinical, radiographical, pathologic, and treatment features of four patients with intussusception caused by incidental HP, with the aim of providing important insight into the diagnosis and management of these patients. In this paper, the charts of four patients who underwent emergency laparotomy between January 2013 and August 2015 at the First Affiliated Hospital of Zhejiang University, China were reviewed. Patient demographics, presenting symptoms, blood test results, pre-operative imaging, operative procedure, and histopathology were retrospectively reviewed. All four patients, including three males and one female, presented to the emergency room with severe abdominal pain and melena. Routine blood tests revealed hemoglobin levels ranging from 75 to $128 \mathrm{~g} / \mathrm{L}$. Contrast-enhanced computed tomography (CT) confirmed lesions involving the ileum with intussusception and bowel obstruction, and all cases immediately underwent emergency laparotomy. All cases were subsequently diagnosed with HP according to histopathology. HP should therefore be considered as a rare but possible differential diagnosis for gastrointestinal bleeding and bowel intussusception, and as a possible cause of these conditions.
\end{abstract}

Keywords: Heterotopic pancreas (HP); intussusception; gastrointestinal bleeding; surgery; case report

Submitted Mar 07, 2020. Accepted for publication Dec 18, 2020.

doi: 10.21037/atm-20-2294

View this article at: http://dx.doi.org/10.21037/atm-20-2294

\section{Introduction}

Heterotopic pancreas (HP), also known as ectopic or aberrant pancreas, is a congenital anomaly defined as aberrantly located pancreatic tissue without anatomical or vascular connection to the pancreas (1). HP can appear anywhere in the abdominal cavity, with common sites including the stomach, duodenum, and proximal jejunum. As the majority of cases are asymptomatic and the reported incidence is therefore very low, most cases are found on autopsy or via laparotomy.

Intussusception of the bowel is defined as the invagination of one portion of the bowel into an immediately adjacent portion (2). Intussusception is common in children but rare in adults, with Azar et al. (3) reporting adult intussusception to represent only $5 \%$ of cases.

This study reports four intussusception cases at the First Affiliated Hospital of Zhejiang University, between January 2013 and August 2015, with an average patient age of 28 years old. Patients presented with abdominal pain as their main symptom, accompanied by gastrointestinal bleeding and various other symptoms. Charts were analyzed for patient demographics, presenting symptoms, blood test results, pre-operative imaging, operative 

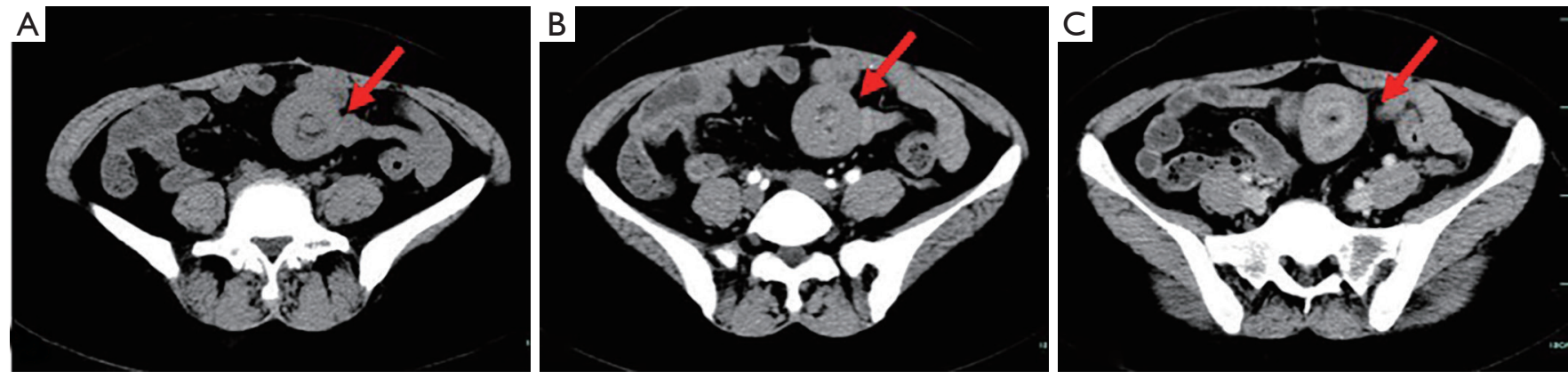

Figure 1 CT scan revealed an ileal mass, intussusception with thickening of the colic wall, and slight proximal intestinal dilation (red arrow). Non-contrast enhanced phase (A), arterial phase (B), and venous phase (C). CT, computed tomography.
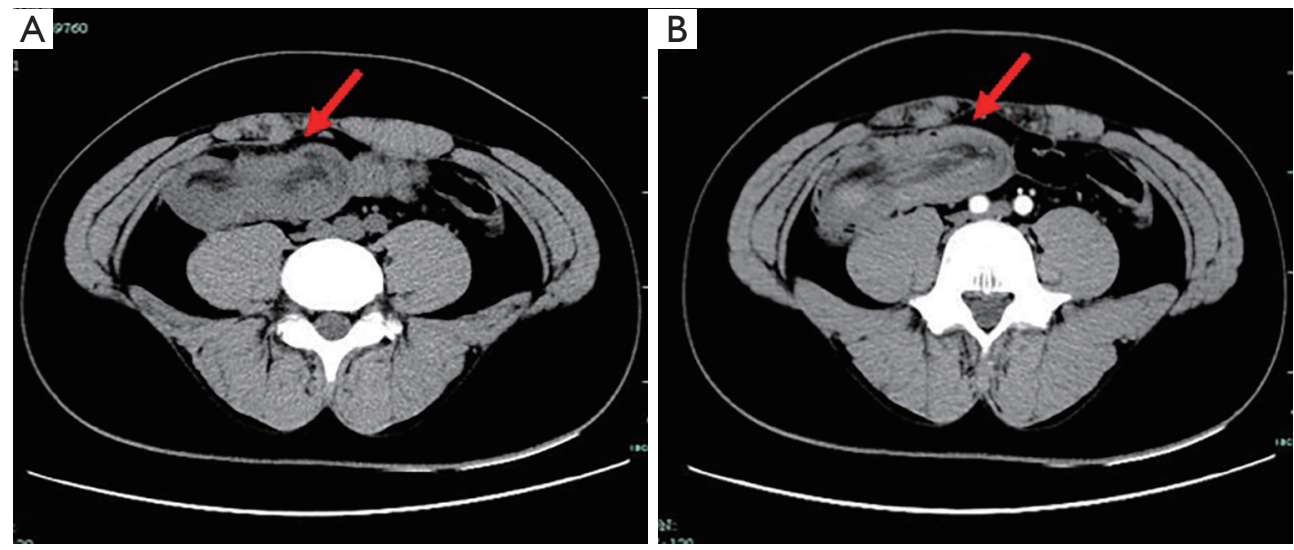

Figure 2 CT scan showed bowel obstruction and intussusception (red arrow). Non-contrast enhanced phase (A) and arterial phase (B). CT, computed tomography.

procedure, and pathologic evaluation. All cases underwent emergency laparotomy and were diagnosed with ileoileal intussusception and gastrointestinal bleeding caused by HP. We present the following cases in accordance with the CARE reporting checklist (available at http://dx.doi. org/10.21037/atm-20-2294) (4).

\section{Case presentation}

Case 1 was a 42-year-old woman referred to our hospital because of abdominal pain and melena lasting 3 months. On assessment, the patient appeared apprehensive and pale. Physical examination revealed tenderness in the right lower quadrant, with no palpable lump. Laboratory investigations revealed a hemoglobin level of $85 \mathrm{~g} / \mathrm{L}$. Intussusception was suspected and confirmed on abdominal ultrasound. Computed tomography (CT) imaging revealed an ileal mass, intussusception with thickening of the colic wall, and slight proximal intestinal dilation (Figure 1). An emergency laparotomy was performed immediately which revealed a submucosal lipoma (measuring $5 \mathrm{~cm} \times 4 \mathrm{~cm}$ ) causing intussusceptions; this was subsequently removed along with part of the small intestine. Pathologic examination suggested an ileo-ileal intussusception secondary to a $5 \mathrm{~cm}$ submucosal lipoma with HP. The patient recovered uneventfully and was discharged 8 days after the operation.

Case 2 was a 17 -year-old boy who presented with intermittent dull abdominal pain and melena for 1 month, and was admitted to hospital for further evaluation. Physical examination revealed an abdominal mass in the right lower quadrant; however, there were no signs of peritonitis. Blood tests showed a low hemoglobin level of $75 \mathrm{~g} / \mathrm{L}$, while gastroscopy, capsule endoscopy, and colonoscopy were unremarkable. Abdominal and pelvic CT showed bowel obstruction and intussusception with a $5 \mathrm{~cm} \times 2 \mathrm{~cm}$ mass (Figure 2). Partial ileal resection of the intussusception 

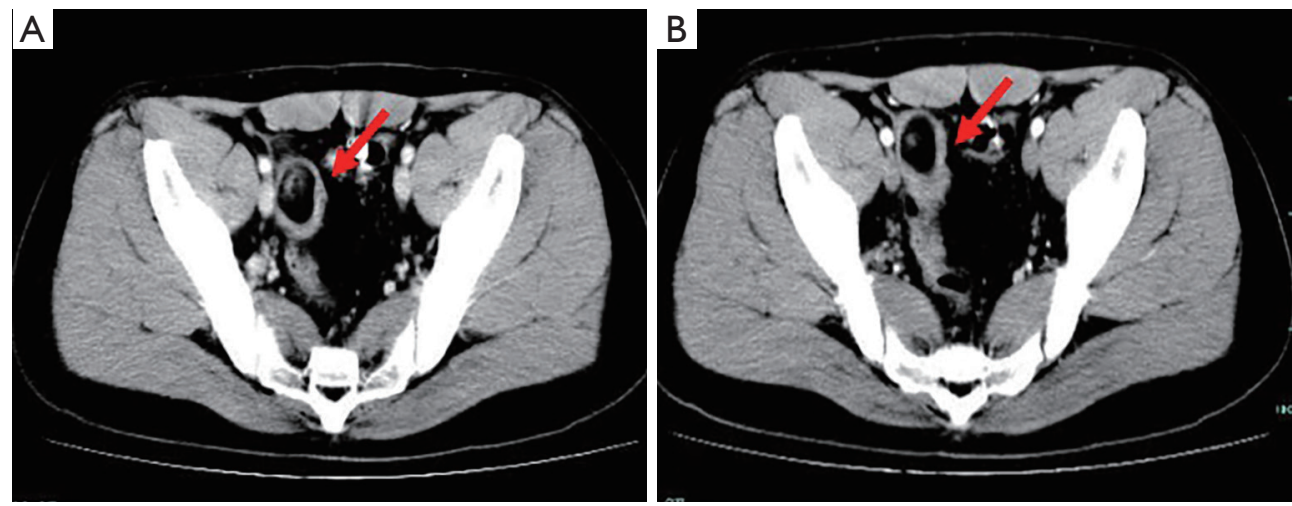

Figure 3 CT scan revealed an ileal intussusception with an abundant fatty component inside (red arrow). Arterial phase (A) and venous phase (B). CT, computed tomography.

was performed, followed by a side-to-side anastomosis. Histopathological analysis of the specimen revealed a benign ileum with $\mathrm{HP}$, with no evidence of malignancy. $\mathrm{He}$ had no further abdominal pain or melena after surgery.

Case 3 was a 27 -year-old man who presented with a 5 -year history of intermittent and progressive abdominal pain and melena. Capsule endoscopy 5 years prior had revealed small intestine polyps with multiple venous malformations; however, all symptoms improved with pharmacological management. The patient was later admitted to hospital with recurrent abdominal cramping. Physical examination was unremarkable, and laboratory data were negative; however, fecal occult blood was positive, and CT revealed an ileal intussusception (Figure 3). A $3 \mathrm{~cm}$ tubular structure with an abundant fatty component was found at the proximal end of the intussusception. Due to the presence of melena and an associated hemoglobin drop from 108 to $91 \mathrm{~g} / \mathrm{L}$ in 3 days, the patient underwent emergency laparotomy where ileo-ileal intussusception was found approximately $140 \mathrm{~cm}$ from the ileocecal valve. A segmental ileal resection with ileoileostomy was performed. Histological examination was typical of HP tissue, and the patient was discharged 5 days later following an unremarkable postoperative course.

Case 4 was a 26 -year-old man who presented to the emergency room with severe abdominal pain and bilious vomiting. Physical examination showed hyperactive bowel sounds and mild generalized abdominal tenderness without guarding or rigidity, but no rebound tenderness. Biological examination did not yield significant results; however, routine blood tests revealed a hemoglobin level of $128 \mathrm{~g} / \mathrm{L}$, and fecal occult blood was positive. CT revealed a large pedunculated mass with intussusception of the terminal ileum (Figure 4), and emergency laparotomy was subsequently performed. The invaginated segment was situated approximately $90 \mathrm{~cm}$ from the ileocecal valve, and there was an firm ovoid mass measuring $5 \mathrm{~cm} \times 4 \mathrm{~cm}$. The ileum, including the intussusception, was removed and primary side-to-side anastomosis was performed. Histopathology showed complete excision of the mass, which contained heterotopic pancreatic tissue. The patient was discharged home on postoperative day 8 . The study was approved by the Ethics Committee of the First Affiliated Hospital, School of Medicine, Zhejiang University, China (No. 2020-93) and conducted in accordance with the Declaration of Helsinki (as revised in 2013). Written informed consent was obtained from the patients for publication of this manuscript and any accompanying images.

\section{Discussion}

In this paper we describe a case series of four patients who underwent emergency laparotomy for ileo-ileal intussusception and gastrointestinal bleeding with a final pathologic evaluation of HP. Although this provides useful insights for future diagnosis and management, unfortunately, these four cases show that diagnosis prior to surgery is difficult and ultimately requires postoperative histopathology. Table 1 summarizes the clinical findings, pre-operative imaging, and operative procedure in these cases, while a timeline of cases is illustrated in Table 2.

$\mathrm{HP}$ is a congenital malformation where isolated pancreatic tissue grows outside the pancreas without 

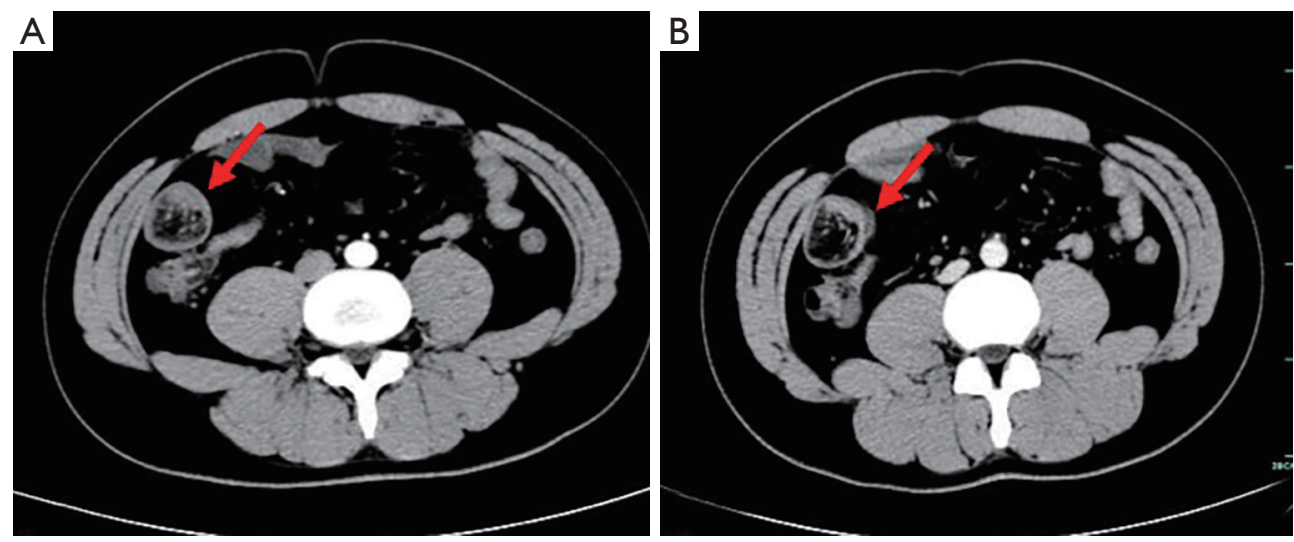

Figure 4 CT scan revealed a large pedunculated mass involving the terminal ileum with intussusception (red arrow). Arterial phase (A) and venous phase (B). CT, computed tomography.

Table 1 Patient demographics

\begin{tabular}{|c|c|c|c|c|c|c|c|}
\hline Patient & $\begin{array}{l}\text { Age, } \\
\text { years }\end{array}$ & Gender & Presentation & $\begin{array}{c}\text { Pre-operative } \\
\mathrm{Hb}, \mathrm{g} / \mathrm{L}\end{array}$ & CT findings & $\begin{array}{c}\text { Operative } \\
\text { management }\end{array}$ & $\begin{array}{l}\text { Pathologic } \\
\text { examination }\end{array}$ \\
\hline 1 & 42 & $\mathrm{~F}$ & $\begin{array}{l}\text { Abdominal pain } \\
\text { and melena }\end{array}$ & 85 & $\begin{array}{l}\text { Ileal mass }(5 \mathrm{~cm} \times 4 \mathrm{~cm}) \\
\text { with intussusception and } \\
\text { bowel obstruction }\end{array}$ & $\begin{array}{l}\text { Resection of the } \\
\text { ileum with side-to- } \\
\text { side anastomosis }\end{array}$ & $\begin{array}{c}\text { Submucosa } \\
\text { lipoma with } \\
\text { heterotopic } \\
\text { pancreas }\end{array}$ \\
\hline 2 & 17 & $M$ & $\begin{array}{l}\text { Intermittent } \\
\text { abdominal pain } \\
\text { and melena }\end{array}$ & 75 & $\begin{array}{l}\text { Bowel obstruction and } \\
\text { intussusception with a } \\
\text { mass }(5 \mathrm{~cm} \times 2 \mathrm{~cm})\end{array}$ & $\begin{array}{l}\text { Resection of the } \\
\text { tumor with side-to- } \\
\text { side anastomosis }\end{array}$ & $\begin{array}{c}\text { Heterotopic } \\
\text { pancreatic } \\
\text { tissue }\end{array}$ \\
\hline 3 & 27 & $M$ & $\begin{array}{l}\text { Abdominal pain } \\
\text { and melena }\end{array}$ & 91 & $\begin{array}{c}\text { An ileal intussusception } \\
\text { with a } 3 \mathrm{~cm} \text { tubular } \\
\text { structure }\end{array}$ & $\begin{array}{l}\text { Resection of the } \\
\text { ileum with end-to- } \\
\text { end anastomosis }\end{array}$ & $\begin{array}{c}\text { Heterotopic } \\
\text { pancreatic } \\
\text { tissue }\end{array}$ \\
\hline 4 & 26 & $M$ & $\begin{array}{l}\text { Severe abdominal } \\
\text { pain and bilious } \\
\text { vomiting }\end{array}$ & 128 & $\begin{array}{l}\text { A lesion }(5 \mathrm{~cm} \times 4 \mathrm{~cm}) \\
\text { involving the terminal ileum } \\
\text { with intussusception and } \\
\text { bowel obstruction }\end{array}$ & $\begin{array}{l}\text { Resection of the } \\
\text { ileum with side-to- } \\
\text { side anastomosis }\end{array}$ & $\begin{array}{c}\text { Heterotopic } \\
\text { pancreatic } \\
\text { tissue }\end{array}$ \\
\hline
\end{tabular}

F, female; M, male; Hb, hemoglobin.

anatomical and vascular connection with normal pancreatic tissue. The HP incidence in autopsy ranges from $0.5 \%$ to $13.5 \%$ in reported series $(5,6)$. In pediatric patients, the condition is more common in females; however, in adults, the condition is more common in males and during the fourth, fifth, and sixth decades of life $(7,8)$. In our reports, three of the four non-pediatric patients were male, with an average age of 28 years.

$\mathrm{HP}$ is common in the upper digestive tract, with the most common sites being the stomach (25-38\%), duodenum (17$36 \%$ ), and jejunum (15-21\%) (9). It has also been observed in the esophagus, ileum, Meckel's diverticulum, mesentery, mediastinum, lung, spleen, gallbladder, liver, and bile duct. Histopathologically, HP is most commonly found in the submucosal layer of the intestinal wall (54\%) followed by the submucosa and lamina propria (23\%); it is seen less in subserous muscle $(11 \%)$ and intrinsic muscle $(8 \%)$, and very uncommonly seen in the whole wall (4\%) (10). While the HP formation mechanism remains unclear, the most tenable explanation is the misplacement theory, whereby the tissue is separated from the pancreas and continues to develop in its abnormal position during the embryo rotation process of dorsal and ventral pancreatic bud fusion $(11,12)$.

The vast majority of patients are asymptomatic; however, 
Table 2 Case timeline

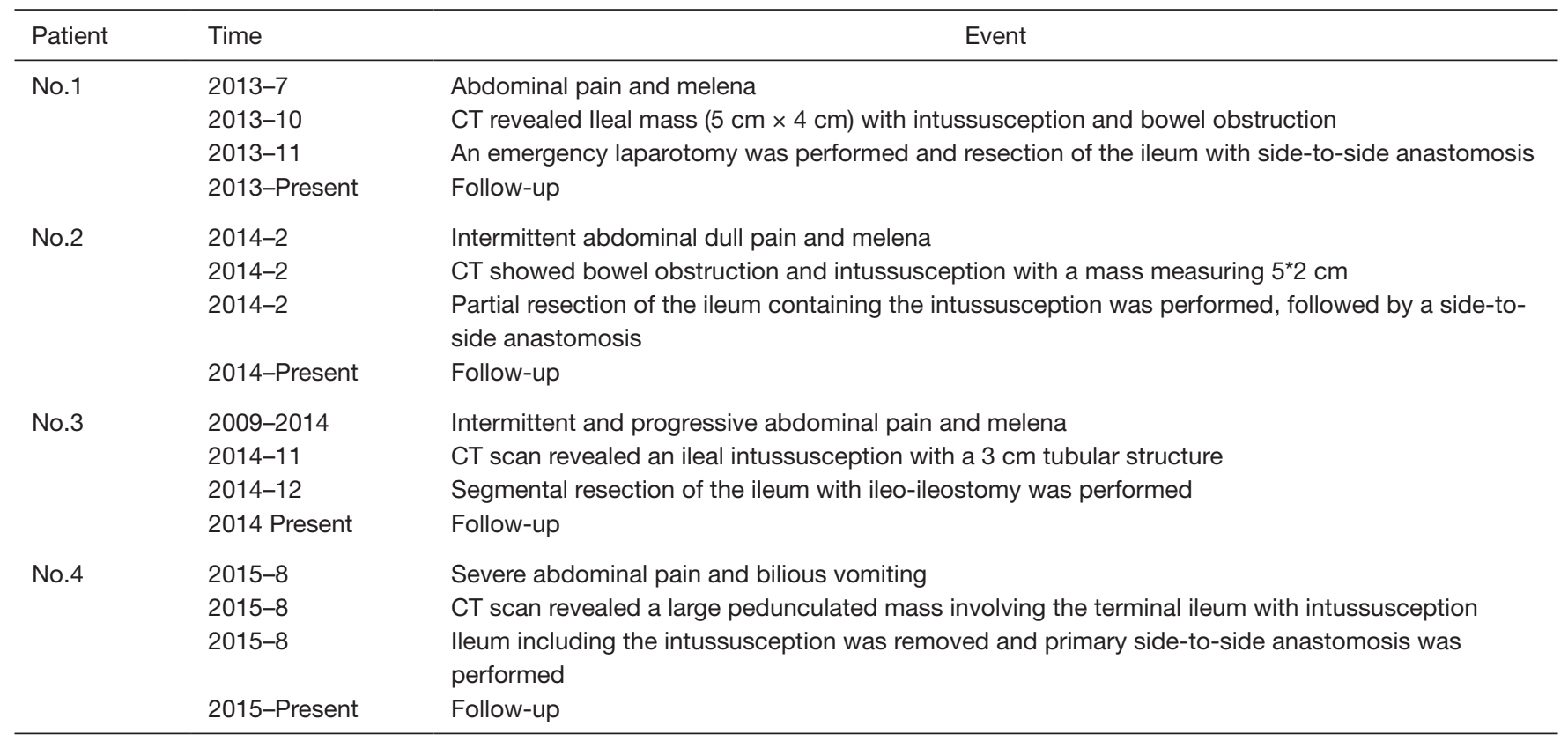

$\mathrm{CT}$, computed tomography.

HP can cause symptoms depending on its location, size, and complications. Complications in the intestine include intussusception, intestinal obstruction, and gastrointestinal bleeding; malignant transformation is also a rare complication, with an incidence of $0.7-1.8 \%$ (13). Consequently, the most common symptoms of HP are abdominal pain, followed by nausea, vomiting, melena, blood stool, and weight loss. In our study, abdominal pain was reported in all four cases, accompanied by gastrointestinal bleeding. All cases had varying degrees of anemia, but no specific laboratory findings.

Some authors believe that imaging is specific in the diagnosis of HP and can distinguish HP from other spaceoccupying lesions. The most common CT finding is a small oval-shaped intramural mass with an unclear margin or differential lobe (5). The enhancement characteristics of HP and normal pancreatic tissue in our cases were consistent, which were related to their histologic composition. That is to say, the lesions dominated by acinar showed strong uniform enhancement after intravenous injection, while the lesions dominated by catheter showed low vascular and magnetic resonance imaging (MRI) inhomogeneity. Both MRI and CT have this characteristic $(5,14)$. Ruan et al. (15) reported that HP in the small bowel with focal fluorodeoxyglucose 18F (18F-FDG) uptake could possibly differentially diagnosis intestinal tumor and tuberculosis.
Endoscopic ultrasonography and endoscopic biopsies are helpful in the diagnosis of HP. Under endoscopic ultrasonography, the most common manifestation of HP is submucous solid mass, which is hypoechoic relative to the hyperechoic submucosa, and isoechoic relative to intrinsic muscle (16); however, endoscopy is of little help in the diagnosis of small intestinal HP in emergency cases where bleeding or obstruction has occurred. In our report, cases 2 and 3 received endoscopic examination-including capsule endoscopy-due to serious gastrointestinal bleeding, but this yielded no positive results; meanwhile, CT showed intussusception with intestinal obstruction or space-occupying lesions. Despite these findings, HP diagnosis was ultimately determined using postoperative pathological results due to the lack of specificity of clinical symptoms, laboratory examination, and endoscopic examination; however, auxiliary examination methods could be considered in making a preoperative diagnosis in adult intussusception cases and gastrointestinal bleeding.

Surgical excision remains the only curative therapy for HP-related intussusception and gastrointestinal bleeding and provides an opportunity for histological diagnosis of potential malignancy. Surgical resection includes laparotomy and laparoscopic surgery; laparotomy provides more comprehensive exploration but greater trauma and surgical scarring, while laparoscopy is less traumatic with minimal 
surgical scars but may miss diagnosis, cause perforation, and present other risks. The treatment of asymptomatic, histologically verified HP, or incidental HP findings during surgery for other abdominal diseases, remains controversial. Some clinicians recommend complete excision in asymptomatic patients for histological confirmation and prevention of future complications, such as malignant transformation, intestinal obstruction, gastrointestinal bleeding, and other serious complications. All our patients underwent emergency laparotomy, recovered well after operation, and had no obvious complications.

\section{Conclusions}

Intussusception caused by HP is relatively rare, with few cases being previously reported. While isolated HP causing ileo-ileal intussusception and gastrointestinal bleeding is rare, the possibility of HP should be considered as part of differential diagnosis in these cases. CT could provide useful preoperative information; however, many cases are undetected or misdiagnosed on imaging and ultimately require emergency laparotomy for diagnosis. This report is clinically important as it is one of few published studies on intussusception and gastrointestinal bleeding due to HP.

\section{Acknowledgments}

Funding: None.

\section{Footnote}

Reporting Checklist: The authors have completed the CARE reporting checklist. Available at http://dx.doi.org/10.21037/ atm-20-2294

Conflicts of Interest: All authors have completed the ICMJE uniform disclosure form (available at http://dx.doi. org/10.21037/atm-20-2294). The authors have no conflicts of interest to declare.

Ethical Statement: The authors are accountable for all aspects of the work in ensuring that questions related to the accuracy or integrity of any part of the work are appropriately investigated and resolved. The study was approved by the Ethics Committee of the First Affiliated Hospital, School of Medicine, Zhejiang University, China (No. 2020-93) and conducted in accordance with the Declaration of Helsinki (as revised in 2013). Written informed consent was obtained from the patients for publication of this manuscript and any accompanying images.

Open Access Statement: This is an Open Access article distributed in accordance with the Creative Commons Attribution-NonCommercial-NoDerivs 4.0 International License (CC BY-NC-ND 4.0), which permits the noncommercial replication and distribution of the article with the strict proviso that no changes or edits are made and the original work is properly cited (including links to both the formal publication through the relevant DOI and the license). See: https://creativecommons.org/licenses/by-nc-nd/4.0/.

\section{References}

1. Juricic M, Djagbare DY, Carmassi M, et al. Heterotopic pancreas without Meckel's diverticulum in children as unique cause of gastrointestinal bleeding: think about it! Surg Radiol Anat 2018;40:963-5.

2. Marinis A, Yiallourou A, Samanides L, et al. Intussusception of the bowel in adults: a review. World J Gastroenterol 2009;15:407-11.

3. Azar T, Berger DL. Adult intussusception. Ann Surg 1997;226:134-8.

4. Riley DS, Barber MS, Kienle GS, et al. CARE guidelines for case reports: explanation and elaboration document. J Clin Epidemiol 2017;89:218-35.

5. Rezvani M, Menias C, Sandrasegaran K, et al. Heterotopic Pancreas: Histopathologic Features, Imaging Findings, and Complications. Radiographics 2017;37:484-99.

6. Dolan RV, ReMine WH, Dockerty MB. The Fate of Heterotopic Pancreatic Tissue, a study of 212 cases. Arch Surg 1974;109:762-5.

7. Wei R, Wang QB, Chen QH, et al. Upper gastrointestinal tract heterotopic pancreas: findings from CT and endoscopic imaging with histopathologic correlation. Clin Imaging 2011;35:353-9.

8. Singh S, Batra A, Sangwaiya A, et al. Heterotopic pancreas presenting as ileoileal intussusception. J Surg Case Rep 2012;2012:13.

9. Monier A, Awad A, Szmigielski W, et al. Heterotopic pancreas: a rare cause of ileo-ileal intussusception. Pol J Radiol 2014;79:349-51.

10. Ulrych J, Fryba V, Skalova H, et al. Premalignant and malignant lesions of the heterotopic pancreas in the esophagus: a case report and review of the literature. J Gastrointestin Liver Dis 2015;24:235-9.

11. Shin SS, Jeong YY, Kang HK. Giant Heterotopic 
Pancreas in the Jejunal Mesentery. AJR Am J Roentgenol 2007;189:W262-3.

12. Park E, Kim H, Jung KW, et al. Heterotopic Pancreas in Omphalomesenteric Duct Remnant Results in Persistent Umbilical Discharge. Korean J Pathol 2014;48:323-6.

13. Fukino N, Oida T, Mimatsu K, et al. Adenocarcinoma arising from heterotopic pancreas at the third portion of the duodenum. World J Gastroenterol 2015;21:4082-8.

14. Okuhata Y, Maebayashi T, Furuhashi S, et al.

Cite this article as: Cao $\mathrm{L}, \mathrm{Wu} \mathrm{W}$, Chen $\mathrm{D}$, Hong J, Wu J, Zheng S. Ileo-ileal intussusception and gastrointestinal bleeding caused by incidental heterotopic pancreas: four case reports. Ann Transl Med 2021;9(3):272. doi: 10.21037/atm-20-2294
Characteristics of ectopic pancreas in dynamic gadoliniumenhanced MRI. Abdom Imaging 2010;35:85-7.

15. Ruan M, Liu M, Cheng L, et al. Increased 18F-FDG uptake of heterotopic pancreatitis in the small intestine: A CARE-compliant case report. Medicine (Baltimore) 2016;95:e4465.

16. Shanbhogue AK, Fasih N, Surabhi VR, et al. A clinical and radiologic review of uncommon types and causes of pancreatitis. Radiographics 2009;29:1003-26. 